\title{
Impact of Irrigation Technologies on Rural Households' Poverty Status: the Case of Fogera District, North-Western Ethiopia
}

\author{
S. Solomon, M. Ketema \\ School of Agricultural Economics and Agribusiness, Haramaya University, Ethiopia
}

\begin{abstract}
This study tries to analyze whether irrigation technologies have reduced the incidence, depth, and severity of poverty in Fogera district of the Amhara National Regional State of Ethiopia. It also assesses the possible impact brought about by irrigation technologies on households' per capita consumption expenditure. FosterGreer-Thorbeck (FGT) index and Propensity Score Matching (PSM) were used for analyzing the data collected from 180 farm households through formal survey techniques. The result indicated that annual per capita consumption expenditure of irrigation technology users is better than that of non-users. Among the different irrigation technology user groups, per capita consumption expenditure of diversion irrigation users is higher followed by that of motor pump users and treadle pump users in that order. Results from FGT index showed that users of different irrigation technologies are in a better position in terms of incidence, depth, and severity of poverty as compared to the non-users group. The PSM result also indicated that irrigation has increased per capita consumption expenditure of user households by 21 percent. It is, therefore, necessary to develop small-scale irrigation technologies and to encourage farm households to use the technologies in order to reduce poverty.
\end{abstract}

\section{Keywords:}

Ethiopia, poverty, irrigation technologies, propensity score matching.

\section{Introduction}

Irrigated agriculture has been increasing from time. World irrigated areas have changed from 139 million ha in the 1961 to over 273 million ha in 2001 (IWMI, 2002) and then to 309.6 million ha in 2011 (World Fact Book, 2012). Much of this expansion has taken place in developing countries of Asia (IWMI, 2002). Those regions that have the greatest proportion of cultivated area irrigated (namely East Asia and Pacific and North Africa and Middle East) have experienced the greatest poverty reduction. In Africa, only around 3\% of cropland is irrigated and the region has experienced very little reduction in poverty in 1990s, for instance (World Bank, 2000). These are indications that the differences across different areas and countries in irrigation is an important factor in determining rates of poverty reduction.

Ethiopia is located in a geographical region where it is endowed with a favorable climate which receives a relatively higher amount of rainfall in the region. Much of the water, however, flows across the borders being carried away by the transboundary rivers to the neighboring countries. Many studies and professional estimates indicate that the country has an annual surface runoff of close to 122 billion metric cube of water excluding ground water, and has about 3.7 million hectares of potentially irrigable land (Bekele, 2010). However, reliable food supply is almost impossible due to the temporal imbalance in the distribution of rainfall and the consequential limited availability of the required water at the required period. Consequently, the country remains one of the world's poorest nations with around 25 million people, out of over 80 million, living in extreme poverty.

The Amhara National Regional State where this study was conducted is in the vulnerable regions characterized by subsistence farming which produce predominantly cereal crops for household consumption and local markets. Crop production in the region failed to produce sufficient food for the population due to various reasons including the recurrence of drought in the region and the degradation of the environmental. Like other parts of the Amhara Region, the South Gonder zone is also drought prone area. Many studies show that many districts of the zone are food insufficient. 
However, this area has surface and ground water resources which are not being accessed to full potential for production purposes. The Fogera district located east of Lake Tana includes the Fogera plain which has been identified as land with potential to be irrigated as there is a sufficient water resource. However, the district has not used its resources to full potential due to socio-economic, technical and institutional challenges.

Many households in Fogera district are using irrigation technologies to increase production levels. Different irrigation technologies like diversion irrigation, motor pump, and treadle pump are being practiced by the farmers in the area. On the other hand, there are farmers who are not using irrigation technologies even if their land is on irrigable soils. This is may be because of the fact that some farmers have inadequate knowledge on the benefits of irrigation or that they have various impediments to adopt the available irrigation technologies.

While there is empirical evidence in various countries that irrigation development has a substantial impact on poverty reduction, such impact may be determined by a number of factors including farm level characteristics, irrigated technology characteristics, household level variables, institutional setup and others. Owing to the fact that irrigation can generally contribute in reducing poverty and increasing crop production, it is necessary to look into whether irrigation technology users are significantly better off as compared to non-users in terms of incidence, depth, and severity of poverty and in terms of impact on consumption levels brought about by irrigation. Furthermore, it is also important to assess if there are some differences in consumption levels among the different households using different types of irrigation technologies.

In this connection, available previous studies in the country are very scanty on one hand and are relatively older on the other (Bacha et al., 2009; Van der Berg, Ruben, 2006; Tesfay et al., 2006). Because of the fact that socio-cultural, political and economic features are likely to change overtime, it is necessary to have updated research findings on which preparation and implementation of different policies for improving livelihoods and food security are based. It is, therefore, with this assumption that the current study was carried out in Fogera district of South Gondar zone.

The specific aims of this study were measuring incidence, depth and severity of poverty between users and non users of irrigation and assessing impact of irrigation on households' consumption expenditure as a measure of poverty.

\section{Materials and methods}

\section{Description of the study area}

The study was conducted in Fogera district, South Gondar administrative zone of Amhara National Regional State (ANRS). Fogera district is one of the 10 districts in South Gondar administrative zone. It is bordered with Libo Kemkem district in the North, Dera district in the South, Farta and Estie districts in the East and Lake Tana in the West. Woreta is the district town and is found $625 \mathrm{~km}$ from Addis Ababa, $55 \mathrm{~km}$ from the regional capital, Bahir Dar, and $42 \mathrm{~km}$ from Debre Tabor (Zonal city of South Gondar). According to the relatively recent population census, the district has a total population of 249,824 of which 127,286 are males and the remaining 122,540 are females in 2012. Rural dwellers constitute about 89 percent of the population (CSA, 2013).

The district is divided in to 27 rural and 1 urban kebeles $^{1}$. It encompasses 102,809 ha. The land use constitute 44.1 percent of cultivated land, 23 percent of pasture land, 1.9 percent of forest and bush land, 19.9 percent of land covered with water, 6 percent of land covered with constructions, 1.4 percent of swamp land, and 3.7 percent of wasteland. The district is characterized under Weinadega agro-ecological zone. Its average rainfall ranges between 1,103-1,336 $\mathrm{mm}$. The main rainy season extends from May to September. The district's altitude ranges between 1,774 to 2,410 m.a.s.l. Flat land accounts for 76 percent and mountain and hills the remaining 24 percent. The farming system of the district comprises mixed crop-livestock farming system dominated by crop production.

The district is one of the eight districts bordering Lake Tana and has an estimated water body of 23,354 ha. Gumara and Ribb are the two major permanent rivers in the district. There are also 277 different springs, and 16001 hand-dug wells used for irrigation. The district has about 886 motor pumps, 631 treadle pump and 3 diversion irrigation technologies. A total of 20635 hectare of land was developed with irrigation, according to unpublished

${ }^{1}$ Kebele is the smallest administration unit in the government structure. 
report from Fogera district office of agriculture.

\section{Sources and methods of data collection}

Fogera district was selected purposively. From 27 rural kebeles of the district 16 were purposively identified based on the existence of irrigation technologies and experience of irrigation for long time. At the third stage, 4 kebeles were randomly selected. Then, households in the selected kebeles were stratified into users and non users of irrigation technologies. Irrigation users are defined as those who used lift system irrigation technologies such as treadle pump, motor pump and diversion irrigation. Non-user households are defined as farmers who do not make use of the irrigation technologies mentioned above during the same period. Then a total of 180 households (90 from users and 90 from non users) were selected from the 4 kebeles based on the proportion of participant households in the selected kebeles using random sampling techniques. The numbers of non-participant farmers selected were based on the number of participant farmers in the kebeles (i.e. equal to the number of participants sample size in each kebele). The required data were collected using formal survey methods employing questionnaires prepared for the purpose.

\section{Data analysis}

The Foster-Greer-Thorbeck (FGT) index was used to determine the incidence, depth and severity of poverty between users and non-users of irrigation technologies. It is specified as follows:

$\mathrm{p}_{(\alpha)}=1 / \mathrm{n} \sum_{\mathrm{i}-1}^{\mathrm{q}}\left(\frac{\mathrm{y}_{\mathrm{p}-\mathrm{y}_{\mathrm{i}}}}{\mathrm{y}_{\mathrm{p}}}\right)^{\alpha}$

Where $\mathrm{n}$ is the number of sample households, yi is per capita consumption expenditure (consumption expenditure per adult equivalent) of the $\mathrm{i}^{\text {th }}$ household, $y_{p}$ represents the poverty line, $q$ is the number of households below the poverty line and $\alpha$ is the poverty aversion parameter. The poverty aversion parameter takes a value of 0,1 , or 2 . If $\alpha=0$, then the result $(p)$ is poverty head count ratio, which measures the incidence of poverty within the sample. When $\alpha=1$, the result $(p)$ is a poverty gap index, which measures depth of poverty or the aggregate consumption shortfall of the poor from the poverty line. Finally, if $\alpha=2$, the result $(p)$ is a squared poverty gap, which measures the severity or intensity of poverty.

To isolate the independent impact of participation in irrigation on poverty reduction, propensity score matching (PSM) was used. A logit model was used to estimate propensity scores using a composite of pre-intervention characteristics of the sampled households (Rosenbaum, Rubin, 1983) and matching was performed using propensity scores of each observation. In estimating the logit model, the dependent variable was participation in irrigation, which takes the value of 1 if a household is irrigation technology user and 0 otherwise.

The cumulative logistic probability function is specified as

$$
P_{i}=F\left(Z_{i}\right)=F\left(\alpha+\sum \beta_{t} X_{t i}\right)=\left(\frac{1}{1+e^{-\left(\alpha+\sum \beta_{t} X_{t i}\right)}}\right)
$$

Where:

e represents the base of natural logarithms $(\approx 2.718)$

$X_{t i} \quad$ represents the th explanatory variable $(\mathrm{t}=1,2, \ldots, \mathrm{m})$ for the ith individual

$P_{i} \quad$ is the probability that ith individual will make a certain choice (in this case use of irrigation technology) given $m$ explanatory variables

$\alpha \& \beta_{t}$ are parameters to be estimated $(t=1,2, \ldots, m$; $m$ is number of explanatory variables).

Interpretation of the coefficients will be understandable if the logistic model is written in terms of the odds and log of odds. The odds ratio implies the ratio of the probability that an individual would choose an alternative $\left(P_{i}\right)$ to the probability that he/she would not choose it $\left(1-P_{i}\right)$.

But,

$\left(1-P_{i}\right)=\frac{1}{1+e^{Z_{i}}}$

Therefore,

$\left(\frac{P_{i}}{1-P_{i}}\right)=\left(\frac{1+e^{Z_{i}}}{1+e^{-Z_{i}}}\right)=e^{Z_{i}}$

Or,

$\left(\frac{P_{i}}{1-P_{i}}\right)=\left(\frac{1+e^{Z_{i}}}{1+e^{-Z_{i}}}\right)=e^{\left(\alpha+\sum \beta_{t} X_{t i}\right)}$

Taking the natural logarithm of equation (5) will result in what is known as the logit model as indicated below: 


$$
Z_{i}=\ln \left(\frac{P_{i}}{1-P_{i}}\right)=\alpha+\beta_{1} X_{1 i}+\beta_{2} X_{2 i}+\ldots+\beta_{m i} X_{m i}
$$

If the disturbance term $U_{i}$ is taken in to account, the logit model becomes

$$
Z_{i}=\alpha+\sum \beta_{t} X_{t i}+U_{i}
$$

After running the logit model, then the common support region where the values of propensity scores of both users and comparison groups can be found was identified. The region of common support was defined by dropping observations below the maximum of the minimums and above the minimum of the maximums of the balancing scores between the two groups (Diaz, Handa, 2005). Then the average treatment effect on treated (ATT) are only determined in the region of common support (Caliendo, Kopeinig, 2008).

The next step in propensity score matching is to get the matching algorithm which best matches the treated observations with untreated based on the propensity scores from the preceding step. Treatment, in this case, is use of irrigation technologies. There are different matching estimators in theory. According to Caliendo and Kopeinig (2008), the most commonly applied matching estimators are nearest neighbor matching, Caliper and Radius matching, Stratification and Interval matching, Kernel and local linear matching. All matching estimators contrast the outcome of a treated individual with outcomes of comparison group members (Caliendo, Kopeinig, 2008).

To estimate the effect of irrigation technologies to a given outcome ${ }^{2}$ (consumption expenditure per adult equivalent), is specified as:

$C=\frac{\sum_{i=1}^{p} C_{i j 1}-\sum_{i=1}^{N P} C_{i j 0}}{P}$

Where, $C_{i j l}$ is the post intervention per capita consumption expenditure of household $\mathrm{j}, C_{i j 0}$ is the per capita consumption expenditure of the $i^{\text {th }}$ non-participant matched to the jth participant, $P$ is the total number of participants (users of irrigation), $N P$ is the total number of non-participants (non-users of irrigation) and $C$ is difference in per capita consumption expenditure in Ethiopian birr.

Then the average effect of use of irrigation technologies on outcome variables (consumption

\footnotetext{
2 Keeping conditional independence assumption and common support (overlap) assumption
}

expenditure per adult equivalent) was computed and it was specified as:

$\tau_{i}=Y_{i}\left(D_{i}=1\right)-Y_{i}\left(D_{i}=0\right)$

Where $\tau_{i}$ is treatment effect (effect due to use of irrigation technology), $Y_{i}$ is the outcome on household, $D_{i}$ is whether household $i$ has got the treatment or not (i.e. whether a household used irrigation technology or not).

However, one should notice that $\tau_{i}=Y_{i}\left(D_{i}=1\right)$ and $\tau_{i}=Y_{i}\left(D_{i}=0\right)$ cannot be observed for the same household at the same time. Depending on the position of households in the treatment (intervention participation), either $\tau_{i}=Y_{i}\left(D_{i}=1\right)$ or $\tau_{i}=Y_{i}\left(D_{i}=0\right)$ is unobserved outcome (called counterfactual outcome). Due to this fact, estimating household's treatment effect is not possible. One has to shift to estimate the average treatment effect of the population than the individual one. The most commonly used average treatment effect estimation is the average treatment effect on the treated $\left(\tau_{\mathrm{ATT}}\right)$ and is specified as

$\tau_{A T T}=E(\tau \mid D=1)=E[Y(1) \mid D=1]-E[Y(0) \mid D=1]$

As the counterfactual mean for those being treated, $E[Y(1) \mid D=1]$ is not observed, one has to choose a proper substitute for it in order to estimate ATT. One may think to use the mean outcome of the untreated households, $E[Y(1) \mid D=0]$ as a substitute to the counterfactual mean for those being treated, $E[Y(1) \mid D=1]$. However, this is not a good idea especially in non-experimental studies. Because, it is most likely that components which determine the treatment decision also determine the outcome variables of interest.

For our particular case, variables that determine household's decision to use irrigation technology could also affect household's consumption expenditure per adult equivalent. Therefore, the outcomes of individuals from treatment and comparison group would differ in the absence of treatment leading to a self selection bias.

By rearranging and subtracting $E[Y(1) \mid D=1]$ form both sides, one can get the following specification for ATT.

$$
\begin{aligned}
E[Y(1) \mid D=1] & -E[Y(0) \mid D=0]=\tau_{A T T} \\
& +E[Y(0) \mid D=1]-E[Y(0) \mid D=0]
\end{aligned}
$$

Both terms in the left hand side are observables and ATT can be identified if and only 
if $E[Y(1) \mid D=1]-E[Y(0) \mid D=0]=0$, i.e. when there is no self selection bias. This condition can be ensured only in social experiment where treatments are assigned to units randomly (i.e. when there is no self section bias). In non-experimental studies one has to introduce some identifying assumption to solve the selection problems. The following are two strong assumptions to solve the selection problem.

Conditional independent assumption: Given a set of observables covariates $(X)$ which are not affected by treatment (in our case, use of the technology), potential outcome (consumption expenditure per adult equivalent) is independent of treatment assignment (independent of how technology use decision is made by households). This assumption implies that the selection is solely based on observable characteristics and variables that influence treatment assignment (use of irrigation technology made by household) and potential outcomes (consumption expenditure per adult equivalent) are simultaneously observed.

Common support region: This assumption rules out perfect predictability of $D$ given $X$. That is $0<P(D=1 \mid X)<1$. This assumption ensures that households with the same $X$ values have a positive relation of being both users and non- users.

Given the above two assumptions, the PSM estimators of ATT can be written as

$\tau_{A T T}^{P S M}=E_{P(x) \mid D=1}\{E[y(1) \mid D=1, P(X)]-E[Y(0) \mid D=0, P(X)]\}$

Where $P(X)$ is the propensity score computed on the covariates $X$. The above equation indicates that the PSM estimators is the mean difference in outcome over the common support, appropriately weighted by the propensity score distribution of participants.

\section{Results and discussion}

\section{Descriptive results}

Descriptive results of the major variables, both for irrigation technology users and non-users, are indicated in Table 1 below together with their units of measurement. According to the results, users of irrigation technologies have higher family size (5.5) as compared to non-users and about $96 \%$ of the user households are headed by male as compared to only $86 \%$ for the non-users. These are mainly related to the labor requirements of the technologies. Mean values of the other variables for the users and non-users are also indicated in Table 1.

Consumption expenditure under different irrigation technology users

Table 2 indicates that as far as irrigation lift technologies and diversion irrigation are concerned, households using diversion irrigation technology have more per-capita consumption expenditure than users of other irrigation technologies. Users of motor pump irrigation technology users are also better off in terms of per capita consumption expenditure than users of treadle pump irrigation users. This is because of the fact that the operational cost of diversion irrigation is minimum or nil in the study area. Since motor pump irrigation technology users are better in income position

\begin{tabular}{llccc}
\hline Variables & Measurements & \multicolumn{3}{c}{ Mean Values } \\
\cline { 3 - 5 } & & All & Users & Non-users \\
\hline Sex of HH head & 1 for male, 0 otherwise & 0.906 & 0.956 & 0.856 \\
Age of the HH head & Year & 42.49 & 42.42 & 42.56 \\
Education level of HH head & 1 for literate, 0 otherwise & 0.317 & 0.40 & 0.233 \\
Family size & Number & 5.18 & 5.47 & 4.89 \\
Distance to market & Kilometers & 5.49 & 4.98 & 6.01 \\
Distance from DAs' office & Kilometers & 2.20 & 2.19 & 2.20 \\
Average distance from farm land & Kilometers & 1.52 & 1.45 & 1.59 \\
Membership to farmers' coops & 1 for member, 0 otherwise & 0.533 & 0.567 & 0.50 \\
Cultivated land size & Hectare & 1.20 & 1.27 & 1.12 \\
Number of oxen owned & Number & 1.59 & 1.79 & 1.38 \\
\hline Source: own elaboration & & & &
\end{tabular}

Table 1: Description of household characteristics by irrigation use. 
than treadle pump users and irrigation non user households they are better off in consumption expenditure.

\section{Comparison of poverty profile}

To estimate poverty line, first the food poverty line was estimated, and then adjusted to account for non-food consumption expenditure. The food poverty line was constructed following the cost of basic needs (CBN) approach. The average quantity of food items that were most frequently consumed by households in the lowest quartile expenditure distribution was derived. These were then converted into calorie consumption and scale up to provide $2200 \mathrm{kcal} /$ person/day, the minimum energy requirement for a person to lead a normal physical life under Ethiopian condition, as estimated by Ethiopian Nutrition Institute and used by similar studies in Ethiopia (Hagos, Holden, 2003; Bacha et al., 2009). To arrive at the food poverty line, this bundle was valued at local market prices in the study area. Therefore, the food poverty line is found to be Birr 1770.37 per person in AE/year. The non-food expenditure component is also calculated using the average food share for households that had failed to attain the food poverty line. The food share for households that had failed to attain the food poverty line is found to be 76.3 percent. This figure is used to estimate allowance of non-food expenditure and found to be Birr 548.99 per person in AE/year and, therefore, gives a total poverty line of Birr 2319.36 per person in AE/year. Hence, when this study refers to 'poor' it means those whose per adult consumption (food and non-food) expenditure per annum falls below 2319.36 Birr at $2010 / 11$ crop prices in the study area.

The FGT index was used to determine the incidence, depth and severity of poverty between users and non-users of irrigation technologies. Based on the above poverty line estimation, the result showed that the headcount index in the area was 16.1 percent (Table 3). About 16.1 percent of the sample households were living below poverty line and unable to fulfill the minimum consumption requirement. This figure is found to be smaller than those reported by other studies in other parts of the country indicating that the study area is in a relatively better position in terms of head count index. The overall poverty gap was 3.4 percent indicating that poor households needed, on average, an additional 3.4 percent of the present expenditure to attain their minimum basic needs. The squared poverty gap was 0.011 showing that there is an inequality among the lowest quartile sample households.

When poverty indices were disaggregated into irrigation technology users and non-users, irrigation users using the absolute overall poverty line of 2319.36 Birr significantly lowered poverty levels in incidence, depth, and severity. The result

\begin{tabular}{|c|c|c|c|c|}
\hline Category & Observations & Mean (Birr) & Std. Deviation & t-value \\
\hline \multicolumn{5}{|c|}{ Irrigation water lift technologies and diversion irrigation } \\
\hline Diversion irrigation & 24 & 4472.40 & 1678.57 & $4.76^{* * *}$ \\
\hline Motor pump & 52 & 3781.83 & 1249.81 & $3.27 * * *$ \\
\hline Treadle & 14 & 3338.42 & 879.08 & 0.69 \\
\hline \multicolumn{5}{|l|}{ Access to irrigation } \\
\hline User & 90 & 3897.01 & 1371.94 & $4.17 * * *$ \\
\hline Non-user & 90 & 3129.52 & 1082.40 & \\
\hline
\end{tabular}

***statistically significant 1 percent probability levels

Source: own elaboration

Table 2: Comparison of per capita consumption expenditure of respondents among the different irrigation technology users and non-users.

\begin{tabular}{lccc}
\hline Category & Head Count Index & Poverty Gap Index & Square Poverty Gap \\
\hline Over all & 0.1611 & 0.0339 & 0.0110 \\
Irrigation technology users & 0.1111 & 0.0167 & 0.0042 \\
Non-users & 0.2111 & 0.0511 & 0.0173 \\
\hline
\end{tabular}

Source: own elaboration

Table 3: Poverty indices of irrigation users and non-users. 
showed 11.1 percent of user households were identified as poor while 21.1 percent of non-user households were identified as poor.

Similarly, depth and severity of poverty are also more pronounced among non-irrigators. The poverty gap index (a measure of depth of poverty) is 1.7 percent for irrigators and 5.1 percent for non-irrigators. This implies that to lift the poor non-irrigators out of poverty, their current consumption level would have to increase by 5.1 percent, while poor farmers from the irrigator group need only 1.7 percent increases from their current consumption level to move above the poverty line. The squared poverty gap index (poverty severity) was 0.0042 to users while 0.0173 to irrigation non-users showing inequality among the poor is higher for non-users.

\section{Econometric results}

The maximum likelihood estimate of the logistic regression model result shows that participation was influenced by four variables. Sex of the household head, educational level, distance from market and number of oxen owned by the household are variables that significantly affected participation of households in irrigation farming (Table 4). After estimating values of irrigation participation (propensity scores) for irrigation users and non users, the second step is matching users and the control group by imposing a common support condition. As shown in Table 5, the estimated propensity scores vary between 0.092 and 0.920 (mean $=0.589)$ for treatment households and between 0.036 and 0.905 (mean $=0.411$ ) for control households. In other words, households whose estimated propensity scores are less than 0.092 and larger than 0.905 are not considered for the matching exercise. As a result of this restriction, four households (one treatment and three control households) were discarded from the analysis.

\begin{tabular}{lcc}
\hline Variables & Coefficients & Standard errors \\
\hline Sex of household head & $1.129^{*}$ & 0.632 \\
Age of household head & -0.013 & 0.152 \\
Level of education of household head & $0.755^{* *}$ & 0.367 \\
Family size & 0.106 & 0.124 \\
Distance from the nearest market & $-0.289^{* *}$ & 0.09 \\
Distance from DA office & -0.088 & 0.141 \\
Distance from farm land & -0.139 & 0.206 \\
Membership to coops/organizations & -0.119 & 0.367 \\
Size of cultivated land & 0.441 & 0.432 \\
Number of oxen owned & $0.561^{* *}$ & 0.257 \\
Constant & -0.921 & 1.178 \\
Sample size(n) & 180 & \\
Pseudo $\mathrm{R}^{2}$ & 0.1375 & \\
LR chi2(10) & 34.31 & \\
Pro>chi2 & 0.0002 & \\
Log likelihood & -107.61 & \\
\hline
\end{tabular}

$*$,** and $* * *$ statistically significant at 10,5 and 1 percent probability levels, respectively Source: own elaboration

Table 4: Logit model results of determinants of households' participation in irrigation technologies.

\begin{tabular}{lccccc}
\hline Group & Obs & Mean & STD & Min & Max \\
\hline Total HHs & 180 & 0.5 & 0.209 & 0.036 & 0.920 \\
Treatment HHs & 90 & 0.589 & 0.169 & 0.092 & 0.920 \\
Control HHs & 90 & 0.411 & 0.209 & 0.036 & 0.905 \\
\hline
\end{tabular}

Source: own elaboration

Table 5: Distribution of estimated propensity scores. 
Alternative matching estimators can be employed in matching the user and comparison households in the common support region. The final choice of a matching estimator can be done taking selection criterion like balancing test, pseudo- $\mathrm{R}^{2}$ and matched sample size. A matching estimator which balances all explanatory variables (i.e., results in insignificant mean differences between the two groups), a model which bears a low pseudo $\mathrm{R}^{2}$ value and results in large matched sample size is a preferable matching algorism (Dehejia, Wahba, 2002).

After looking into the results, it has been found that four nearest neighbor matching is selected. Hence, four nearest neighbor matching is the best estimator for the data at hand based on matching quality criteria. Studies by Diaz and Handa (2005), and Bernard et al. (2007) selected nearest neighbor matching as their matching algorithm method based on matching quality criteria. In this case the individual from the control group is chosen as a matching partner for a treated individual with the least distance in terms of propensity score. Each treatment observation is matched with the average value of its four nearest comparison neighbors, again based on the propensity score distribution (Becker, Ichino, 2002).

After controlling for pre-intervention differences of the user and non user households, per-capita consumption expenditure of the treated group was 3888.01 and the control group has percapita consumption expenditure of 3071.27 birr. The two-group mean difference test was strongly significant at 1 percent level. It has been found that, on average, irrigation user households have significantly increased per capita consumption expenditure by 816.74 birr. That means irrigation has increased per capita consumption of the irrigation technology users by 21 percent. This figure is high especially in areas where rain-fed agriculture is possible with limited scope. This consumption expenditure difference between irrigation users and the control group reflect a household's difference in quality of life and ability to meet basic needs. So there is a great difference in tackling poverty between irrigation users and non-users. The result supported the fact that irrigation reduces poverty as it is also indicated in various other studies (Hussain, Hanjra, 2004).

\section{Conclusion}

Diversion irrigation technology users are at relatively higher standard of living than motor and treadle pump users in terms of per capita consumption (consumption per adult equivalent). Motor pump users have also better standard of living than treadle pump irrigation technology user households. The head count index, the poverty gap index and the severity index showed that users of irrigation technology are better off in terms of incidence, depth, and severity of poverty as compared to non-users of irrigation technologies.

After controlling for pre-intervention differences of the user and non-user households, it has been found that irrigation user households have increased per capita consumption expenditure by 21 percent than non-irrigation technology users supporting the fact that irrigation reduces poverty. The sensitivity test result showed that the impact estimates (ATT) are insensitive to unobserved selection bias and are a pure effect of irrigation technologies on poverty status.

Based on the empirical findings reported in this study, small-scale irrigations using different irrigation water lift technologies and diversion irrigation need to be encouraged to increase crop production and hence reduce poverty. Even though use of irrigation water lift system technologies and diversion irrigation technologies have a strong poverty reduction potential, priority should be given to promotion of diversion irrigation technologies. Its minimum operation costs and ability to poverty reduction made it to be selected but it should be designed appropriately to surface water resources. Unless the landscape and water source prohibit doing so, construction of diversion irrigation is a best strategy.

Motor pump is an appropriate technology for intensive farming especially in areas with undulating and ragged topography having difficulties of diverting water sources to farm lands. Therefore, it is necessary to deliver best quality motor pumps technologies in such areas.

Alleviating oxen power shortage and upgrading education level of farmers need special attention to improve the irrigation system and to motivate farmers towards irrigation technologies participation. Market distance from the producer is also one problem to the area. Facilitating market centers and improving market infrastructures need special attention 
Corresponding author:

Mengistu Ketema

School of Agricultural Economics and Agribusiness

Haramaya University, Ethiopia

Phone: +251255530384,E-mail:mengistuket@gmail.com

\section{References}

[1] Bacha, D., Regassa, N., Bogale, A., Tesfaye, A.. Impact of Small-Scale Irrigation on Household Poverty: Empirical Evidence from the Ambo District in Ethiopia. Irrigation and Drainage. 2009, No. 60, p. 1-10. ISSN 1531-0361.

[2] Bekele, S. Irrigation Potential in Ethiopia: Constraints and Opportunities for Enhancing the System. International Water Management Institute. 2010, 59 p.

[3] Bernard, T., Seyoum, A., Gebre-Madhin, E. Impact of Cooperatives on Smallholders' Commercialization Behavior: Evidence from Ethiopia. Agricultural Economics. 2008, Vol. 39, No. 2, p. 147-161. ISSN 1574-0862.

[4] Becker, O. S., Ichino, A. Estimation of Average Treatment Effects Based on Propensity Scores. The Stata Journal. 2002, Vol. 2, No. 4, p. 358-377. ISSN 1536-8734.

[5] Caliendo, M., Kopeinig, S. Some Practical Guidance for the Implementation of Propensity Score Matching. Journal of Economic Surveys. 2008, Vol. 22, No. 1, p. 31-72. ISSN 1467-6419.

[6] CSA (Central Statistical Authority). Population Projections for year 2012. Population Size by Sex, Area and Density by Region, Zone and Wereda,.2013, Addis Ababa.

[7] Dehejia, R. H., Wahba, S. Propensity Score Matching Methods for Non-Experimental Causal Studies. The Review of Economics and Statistics. 2002, Vol. 84, No. 1, p. 151-161. ISSN 1530-9142.

[8] Diaz, J. J., Handa, S. An Assessment of Propensity Score Matching as a Non Experimental Impact Estimator: Evidence from Mexico's PROGRESA Program. The Journal of Human Resources. 2006, Vol. 41, No. 2, p. 319-345. ISSN 0022-166X, e-ISSN: 1548-8004.

[9] Hagos, F., Holden, S. Rural Household Poverty Dynamics in Northern Ethiopia 1997-2000, Analysis of Determinants of Poverty, Department of Economics and Social Sciences. 2003, Norway, 35 p.

[10] Hussain, I., Hanjra, M. A. Irrigation and Poverty Alleviation: Review of the Empirical Evidence. Irrigation and Drainage. 2004, No. 53, p. 1-15. ISSN 1531-0361.

[11] International Water Management Institute (IWMI). World Irrigation and World Water Statistics 2002 with a Guide to Data Sources. International Water Management Institute: Colombo, Sri Lanka, 2002.

[12] Van Den Berg, M., Ruben, R., Small-Scale irrigation and income distribution in Ethiopia, The Journal of Development Studies. 2006, Vol. 42, No. 5, p. 868-880. ISSN 0022-0388.

[13] Rosenbaum, P. R., Rubin, D. B. The Central Role of the Propensity Score in Observational Studies for Causal Effects. Biometrika. 1983, Vol. 70, No. 1, p. 41-55. ISSN 1464-3510.

[14] Tesfay, A, Bogale, A, Bacha, D, Namara, R. Impact of small-scale irrigation on households' food security: Evidence from Godino and Filtino irrigation schemes in Ada Liven district, Ethiopia. Journal of Irrigation and Drainage Systems. 2006, No. 22, p. 145-158.

[15] World Bank. World Development Report 2000-1: Attacking Poverty. Washington DC: The World Bank, 2000.

[16] World Fact Book. Irrigated Area, 2012. 